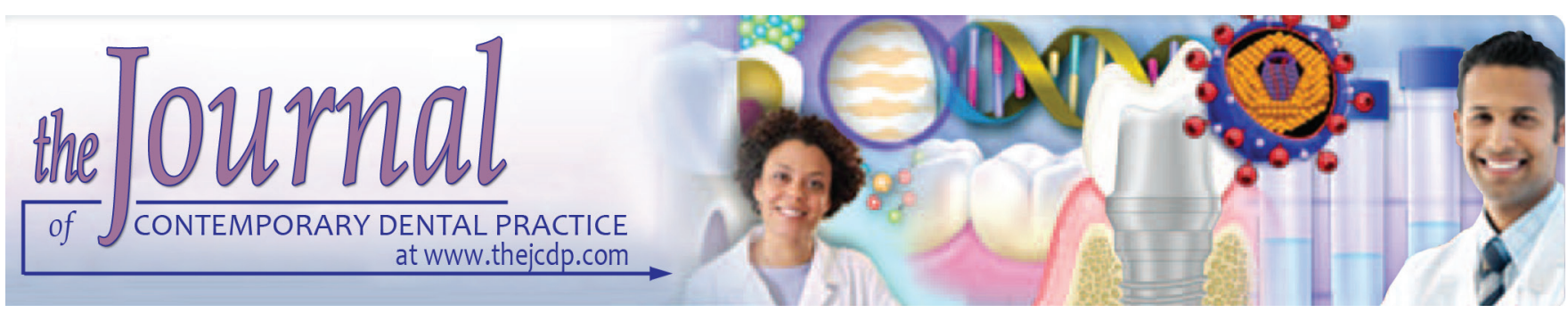

\title{
Oral Rehabilitation of Young Adult with Amelogenesis Imperfecta
}

\author{
${ }^{1}$ Vincent WS Leung, ${ }^{2}$ Bernard Low, ${ }^{3}$ Yanqi Yang, ${ }^{4}$ Michael G Botelho
}

\begin{abstract}
Background: Amelogenesis imperfecta is a heterogeneous group of hereditary disorders that affect the enamel formation of the primary and permanent dentitions while the remaining tooth structure is normal. Appropriate patient care is necessary to prevent adverse effects on dental oral health, dental disfigurement, and psychological well-being.
\end{abstract}

Aim: This clinical report presents a 27-year-old Chinese male with amelogenesis imperfecta $(\mathrm{Al})$ and his restorative management.

Case report: This clinical report presents a 27-year-old Chinese male with $\mathrm{Al}$ and his restorative management. Extraoral examination showed a skeletal class III profile and increased lower facial proportion. Intraorally, all the permanent dentition was hypoplastic with noticeable tooth surface loss and a yellowbrown appearance. This was complicated with a mild malocclusion and food packing on his posterior teeth. The patient wanted to improve his appearance and masticatory efficiency. Orthodontic treatment was performed to treat the mild malocclusion and create physiological interproximal spacing to minimize tooth preparation and facilitate oral hygiene.

Conclusion: This report demonstrates how a multidisciplinary approach for the management of Al can achieve a predictable, functional, and esthetic outcome. Orthodontic treatment facilitated a conservative prosthodontic treatment outcome by selectively increasing interproximal space, minimizing tooth

${ }^{1}$ Private Practitioner, Shop B, G/F, Millennium Court, 72 Shau Kei Wan Road, Sai Wan Ho, Hong Kong

${ }^{2}$ Private Practitioner, 318 Glen Osmond Rd, Myrtle Bank, SA 5064

${ }^{3}$ Department of Orthodontics, Faculty of Dentistry, The University of Hong Kong, The Prince Philip Dental Hospital, Sai Ying Pun Hong Kong, China

${ }^{4}$ Department of Prosthodontics, Faculty of Dentistry, The University of Hong Kong, The Prince Philip Dental Hospital, Sai Ying Pun, Hong Kong, China

Corresponding Author: Michael G Botelho, Department of Prosthodontics, The University of Hong Kong, Room 3B19, The Prince Philip Dental Hospital, 34, Hospital Road, Sai Ying Pun Hong Kong, China, e-mail: botelho@hku.hk, e-mail: botelho@ hku.hk preparation, correcting posterior bilateral cross-bite, as well as an anterior reverse overjet and derotation of the canines.

Clinical significance: This case report demonstrates the effective restoration of $\mathrm{Al}$ using a multidisciplinary approach to overcome crowding using a relatively conservative approach.

Keywords: Amelogenesis imperfecta, Full ceramic crown, Orthodontic treatment, Porcelain veneers.

How to cite this article: Leung WS, Low B, Yang $Y$, Botelho MG. Oral Rehabilitation of Young Adult with Amelogenesis Imperfecta. J Contemp Dent Pract 2018;19(5):599-604.

Source of support: Nil

Conflict of interest: None

\section{BACKGROUND}

Amelogenesis imperfecta is a heterogeneous group of hereditary disorders that affect the enamel formation of the primary and permanent dentitions. ${ }^{1}$ There is a wide diversity of enamel malformation observed in AI. Witkop/Sauk classified three major types of $\mathrm{AI}^{2}{ }^{2}$ The diversity of the condition is believed to reflect the differences in the timing during which amelogenesis is affected. There are three major types of AI classified as: hypoplastic, hypocalcified, and hypomaturation. Hypoplastic AI usually appears pitted, thin, and tinged with a yellowbrown color and has a hard texture. Radiographically, the enamel contrasts normally from dentin. Hypocalcified AI enamel shows a normal thickness on eruption, but is weak in structure, and appears opaque and chalky and is easily abraded and detachable from the underlying dentin. Radiographically, the enamel is less radiopaque than dentin. Hypomaturation AI enamel is slightly softer, but is not hypocalcified. The color is opaque, mottled white, yellow and sometimes brown. Radiographically, it shares a similar radiodensity as dentin. A variety of nonenamel manifestations may also be present in AI, such as delayed eruption, congenitally missing teeth, crown resorption, root resorption, pulp calcification, and 
gingival hyperplasia. Some other craniofacial features may involve, such as reverse curve of Spee, anterior open bite, or a vertical growth pattern. ${ }^{3}$

Enamel is derived from epithelial (ectodermal) origin. When the enamel is starting to form after the initiation of dentinogenesis, cells derived from the internal enamel epithelium undergoes three functional stages: presecretory, secretory, and maturation. ${ }^{4}$ The ameloblasts acquire their characteristics and develop the apparatus to secrete the organic matrix at the presecretory stage. Then they secrete the entire thickness of enamel at the secretory stage. Finally, the ameloblasts facilitate inorganic ions to be secreted and exchanged for water and organic content, resulting in a highly organized hydroxyapatie crystal occupying $95 \%$ of the matrix volume, thereby producing the fully mineralized enamel.

\section{CASE REPORT}

A 27-year-old Chinese male was referred to the Prosthodontic Department, Prince Philip Dental Hospital at the University of Hong Kong. He requested to improve his dental appearance and chewing efficiency. He reported having increasing difficulty to grind the food into small enough pieces for swallowing. He also complained of food trapping in between approximal surface where the enamel had cleaved off which was likely responsible for some interproximal dental decay. The appearance and structural integrity of the patient's dentition were significantly compromised. The teeth appeared yellow-brown in color and had a rough and soft surface texture with a marked tooth surface loss of the enamel, especially on the axial surfaces, which resulted in a change of contour of the teeth including loss of interproximal enamel marginal ridges which facilitated food packing. He had no complaints of dentin hypersensitivity.

According to the patient, his father had experienced similar problems and finally became edentulous and is now wearing complete dentures. This motivated the patient to seek treatment for his condition. The medical history was unremarkable and the patient was a nonsmoker.

\section{Extraoral Examination}

The patient presented with increased lower facial proportion and competent lips. There was no facial asymmetry or signs or symptoms of temporal mandibular joint disorders.

\section{Intraoral Examination}

The patient presented with poor oral hygiene, bleeding on gingival probing, although no probing depth was greater than $4 \mathrm{~mm}$. The soft tissues appeared normal and healthy. The enamel was yellow-brown, rough, soft, and easily detachable by an explorer. The crown height was short in the posterior region. Interproximal caries on teeth \#17 mesial, \#16 distal and mesial, \#26 distal, and \#27 mesial were detected due to repeated food trapping in these areas.

The posterior teeth were in bilateral cross-bite with a reversed overjet and the teeth \#12 and \#13 were in reverse overjet also. Teeth \#13 and \#23 were rotated distally. There was minimal overjet and overbite of the anterior teeth, malalignment and mild crowding.

The free-way-space measured was $2 \mathrm{~mm}$. The centric relationship and the centric occlusion were coincided. No occlusal interference was detected during lateral excursion (Fig. 1).

\section{Radiographic Findings}

A panoramic radiograph showed all of the erupted teeth to have a reduced thickness of enamel but with a normal dentin and pulpal appearance. Tooth \#48 was impacted with a normal thickness of enamel, but it was less radiopaque than dentin, and it was difficult to define the dentin-enamel junction (Fig. 2).

\section{Diagnosis}

The patient was diagnosed with a hypoplastic type AI, generalized gingivitis, and caries on teeth \#17M\#16D, M \#26D \#27M. A mild malocclusion with teeth \#12 \#13 in reverse overjet, teeth \#13 and \#23 mesiobuccally rotated and a bilateral posterior cross-bite.

\section{Treatment Objective}

The goal for treatment was to control active dental diseases, restore the stomatognathic function in terms of mastication and speech, prevention of food packing, improve esthetics, and facilitate self-administered oral hygiene care.

\section{Treatment Plan}

Based on the multifactorial nature of this case, a crossdisciplinary approach was required to create space for prosthetic restoration and correct tooth alignment.

A treatment plan was formulated with a key aim of facilitating the prosthodontic outcome for the recreation of posterior interproximal spacing so as to reduce the amount of interproximal tooth preparation and to create a more physiological contour for better oral hygiene practices. This was achieved by way of upper arch expansion and proclination of the upper incisors to create posterior interproximal space. In addition, correction of the posterior, \#12 and \#13 cross-bites, derotation of the teeth \#13 and \#23, and an increase of the anterior overjet were planned. The correction of the malaligned canines would help establish canine guidance. The increase in anterior overjet will also 


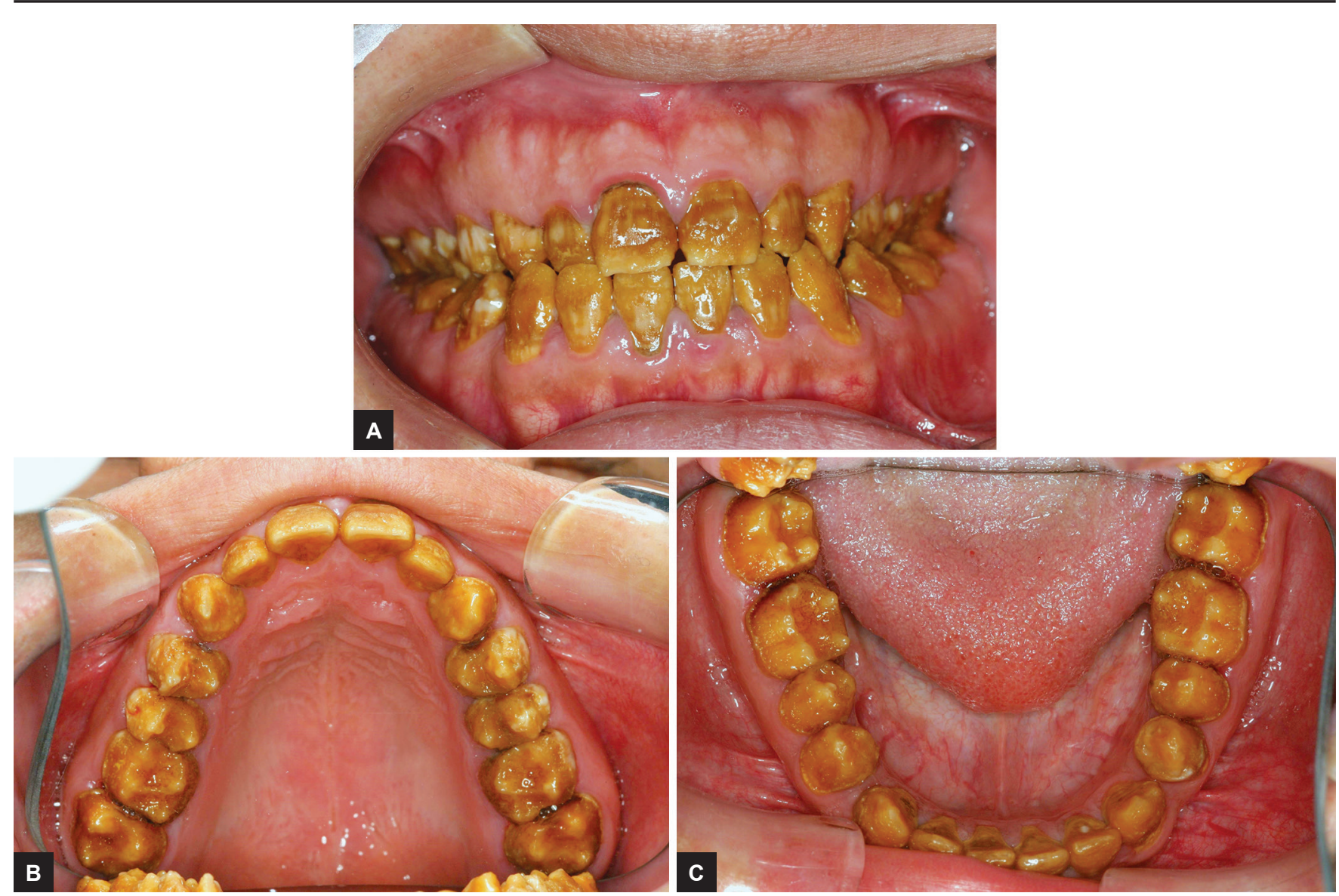

Figs 1A to C: (A) Preoperative frontal view showing severe Al and teeth 13 and 12 cross-bite. (B) Preoperative upper arch showing rotated teeth 13 and 23, loss of tooth surface substance and morphology. (C) Preoperative lower arch showing loss of tooth surface substance and morphology

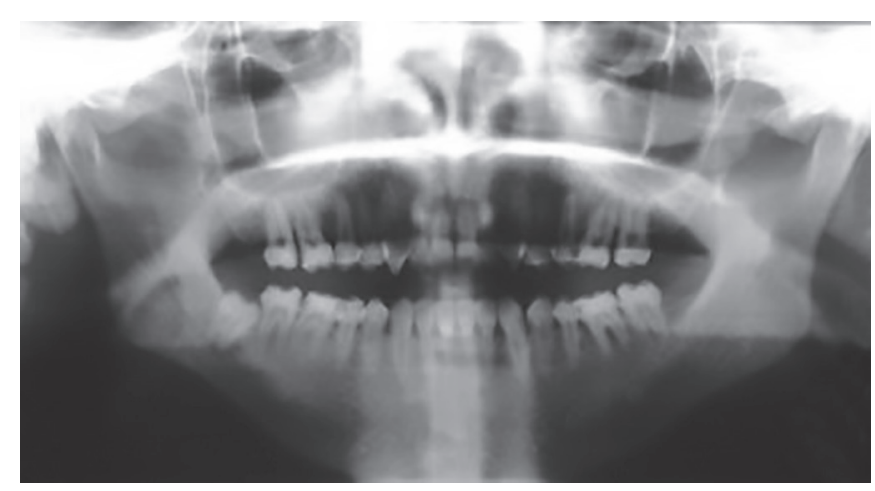

Fig. 2: Preoperative panoramic radiograph showing multiple interproximal caries

help minimize the amount of labial reduction required for the lower incisor restorations in addition; an increase in the prosthetic crown height will help establish the necessary palatal length for incisor disclusion.

In detail, a rapid palatal expander (Fig. 3A) and Crozat appliance (Figs $3 \mathrm{~B}$ and $\mathrm{C}$ ) was planned to correct the cross-bite ${ }^{5}$ and arch wires to derotate teeth \#13 and \#23 as well as procline the upper incisors. After this treatment, the patient would be ready for prosthetic rehabilitation.

The occlusal scheme was designed and planned on a pair of study models, which were mounted on a semi-adjustable articulator (Denar Mark II, WhipMix,
Louisville, Kentucky USA). No change in the occlusal vertical dimension was planned. A diagnostic wax-up was performed to plan the proposed occlusal scheme of incisor and canine disclusion.

The posterior teeth were prepared first. All second molars were prepared to receive full gold crowns. All first molars and all premolars were prepared to receive metal-ceramic crowns. These were temporized with selfcured temporary restorative material (Luxatemp, DMG America, New Jersey, USA) according to the diagnostic wax-up. After this, the upper anterior teeth were prepared to receive six individual PROCERA (Nobel Biocare, Zurich, Switzerland) zirconia crowns, and the lower anterior teeth were prepared to receive six individual IPS Empress (Ivoclar Vivadent, Schaan, Liechtenstein) veneers. The prepared teeth were temporized with selfcured temporary direct restorations (Luxatemp, DMG America, New Jersey, USA) according to the diagnostic wax-up. After clinical evaluation of the planned occlusal scheme, an impression was taken and from this, a study model was used to create a customized incisal guide table by performing "protrusive" movements of the articulator with cold cure acrylic on the incisal table. This would allow the planned occlusal scheme trailed in the mouth to be copied to the definitive restoration. The working 

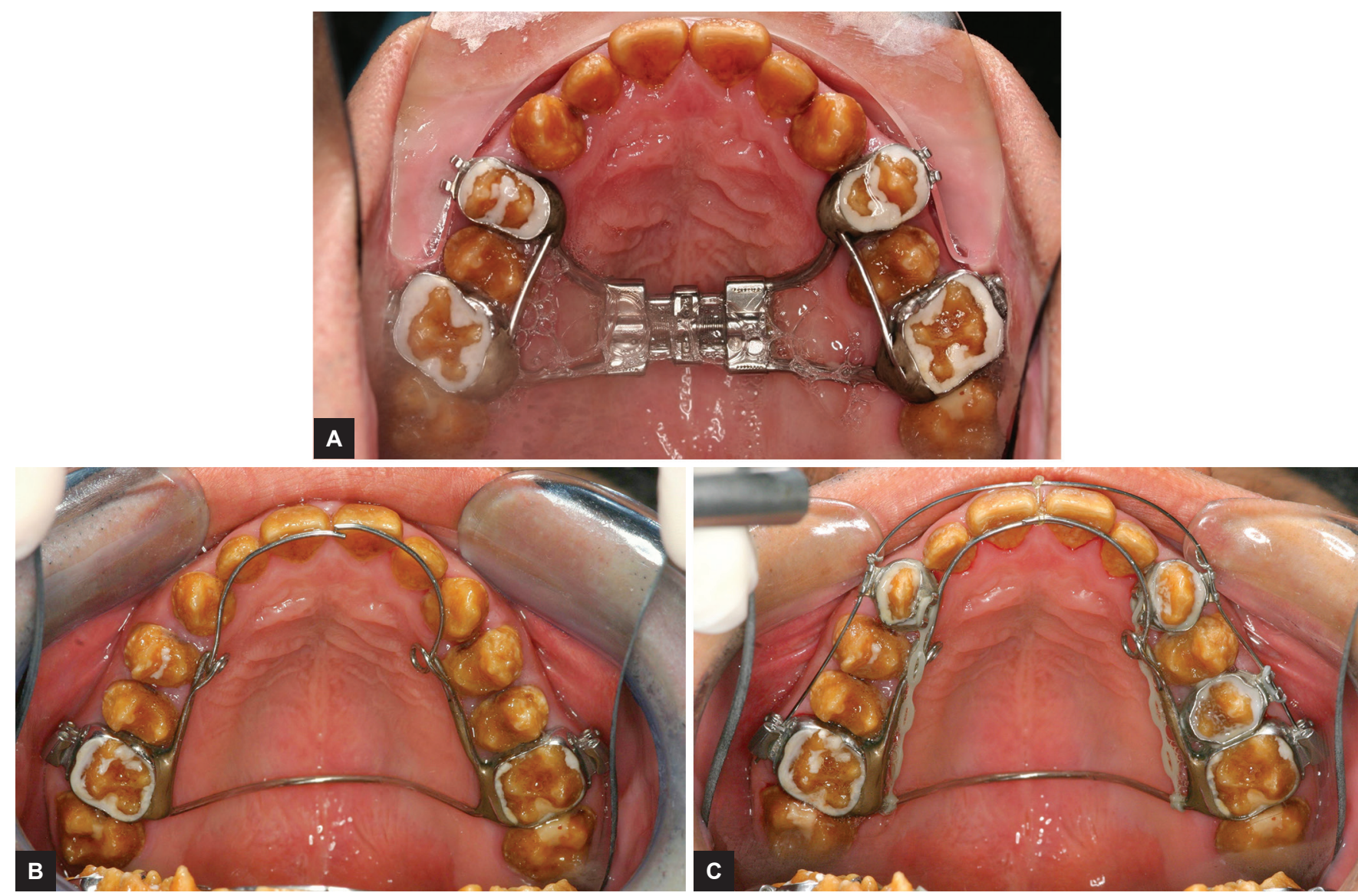

Figs 3A to C: (A) Rapid palatal expander cemented and expanding the upper arch by moving both first molars and first premolars buccally. (B) After 3 months, palatal expansion was done and rapid palatal expander was removed. A Crozat appliance was inserted to provide retention of the expanded arch and proclining the upper anterior teeth. (C) Later on, the canines were banded, an arch wire and power chain were inserted to facilitate the proclination and derotation of the canines. Spaces were created in between the upper anterior teeth

impressions were performed in two phases, upper anterior canine to canine and then posterior tooth segments so as to facilitate control of the occlusal vertical dimension.

Both upper and lower anterior definitive restorations were cemented with duel-cured resin cement (Calibra, DENTSPLY Caulk, Milford, Delaware, USA). At this time, the patient was instructed how to clean the anterior restorations using dental floss and then the posterior segment working impression was taken. The upper premolars and first molars were restored with metal-ceramic crown with metal occlusal surfaces; all the lower premolars and first molars were restored with metal-ceramic crowns and all the second molars were restored with a full gold crown. They were all cemented with dual-cured resin cement (Unicem Rely-X, 3M ESPE dental, St. Paul, Minnesota, USA) (Fig. 4). The patient was then instructed to use dental floss and interdental brushes (TePe, Anaheim, California, USA).

After full mouth rehabilitation, the patient was under regular review and oral hygiene maintenance.

\section{DISCUSSION}

Amelogenesis imperfecta is caused by mutation or altered expression in five genes: AMEL (amelogenin), ENAM (enamelin), FAM83H, MMP20 (matrix metalloproteinase 20), and KLK4 (kallikrein 4) ${ }^{6-16}$ Clinical appearance shows that a spectrum of clinical variability depends on the pattern of inheritance, the mutation involved, the expression of matrix proteins, and biomechanical changes associated with the mutations. The prevalence of AI varies widely with values ranging as 43:10,000 in Turkey, ${ }^{17} 14: 10,000$ in Sweden, ${ }^{18}$ 10:10,000 in Argentina, ${ }^{19}$ $1.25: 10,000$ in Israel, ${ }^{20} 1: 4,000$ to $1: 14,000$ in Western populations. ${ }^{21}$ The global prevalence is $<0.5 \%$ and there is abnormally formed enamel, which is weak in structure like the case presented. This disorder poses a risk of wide range of dental problem, such as caries, periodontal diseases due to repeated food packing between teeth, and difficulties in cleaning. Orthodontic discrepancy and dental esthetic should never be neglected and untreated because they can bring great psychological impact to the patients. Unfortunately, the treatment of AI is always challenging and demanding.

Based on the multifactorial nature of the case complexity, to achieve an optimal outcome, a multidisciplinary approach was adopted. The rapid palatal expander was used to move the upper posterior teeth buccally first, and 

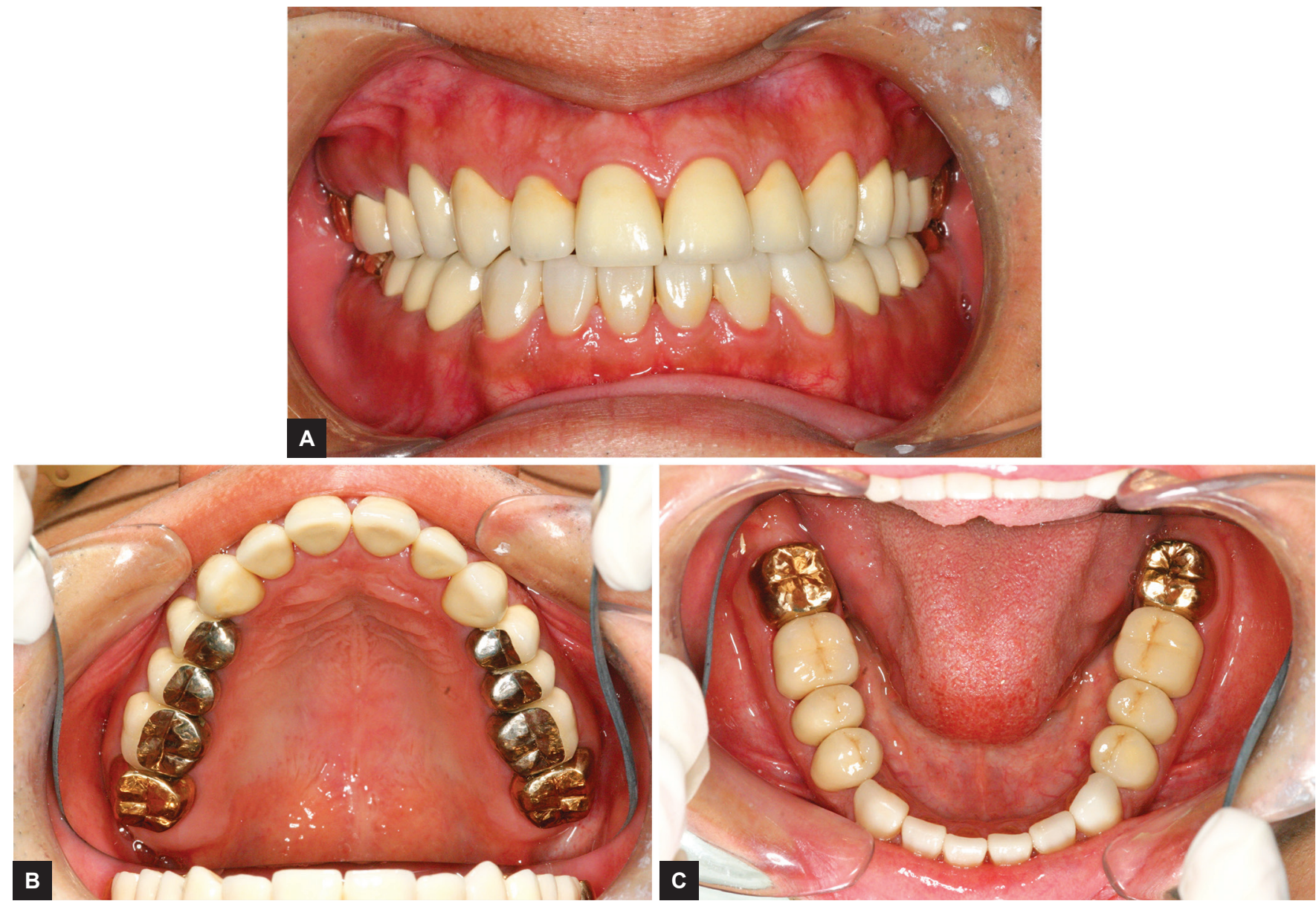

Figs 4A to C: (A) Postoperative frontal view showing corrected alignment of teeth restored with crowns and veneers. (B) Postoperative upper arch showing teeth restored with natural morphology and cleansable proximal contact. (C) Postoperative lower arch showing teeth restored with natural morphology and cleansable proximal contact

then, the Crozat appliance was used to procline the upper incisors and derotate the canines. These movements also expanded the whole upper arch buccally and labially, and by increasing the arch length without increasing the size of the teeth, space between the teeth was created. The creation of these spaces was strategic in reducing the amount of tooth reduction. Overall, all the remaining enamel was compromised being reduced in quality and quantity. In the upper posterior segments, there was a need to recreate interproximal space so as to accommodate physiological contours of dental restorations and permit space for cleansable dental restorations, as the patient had experienced food trapping. In addition, to reduce the need for posterior occlusal tooth preparation, metal occlusal surfaces were provided for all the posterior metal-ceramic crowns apart from the second molars, thereby conserving tooth tissue without significantly compromising the esthetics. The second molars' crown height was limited and therefore, full veneer gold crowns were provided.

The proclination of the upper anterior teeth increased the overjet which in turn provided space for both the upper and lower incisors. In the upper arch, the amount of interproximal and palatal reduction was minimized for

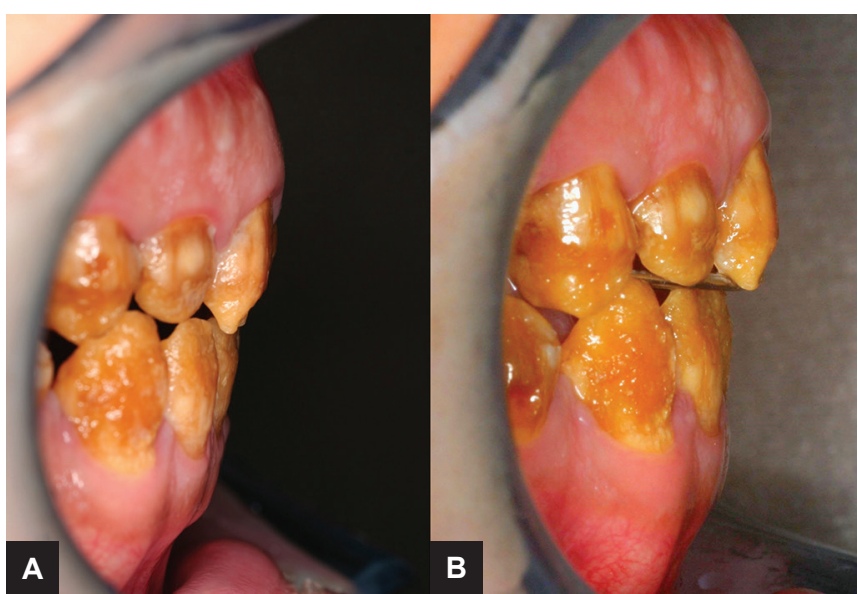

Figs 5A and B: (A) The incisors relationship before Crozat appliance was inserted. (B) The incisors relationship after the treatment by Crozat appliance. Overjet was created, teeth 12 and 13 cross-bite were corrected, and both canines were derotated

the full coverage ceramic restorations. In the lower arch, the created space reduced the amount of tooth preparation required for porcelain laminate veneers (Fig. 5). The derotation of canine improved the appearance and also minimized unnecessary tooth preparation, preserving the vitality of the teeth. 
The protein content of the enamel in these types of cases is increased, ${ }^{22,23}$ which has been shown to impact the effect of acid etching ${ }^{24}$ and which would affect the bond strength; however, there was no observed failure of lower anterior restoration reported at the review appointment.

\section{CONCLUSION}

Treatment for AI patients is challenging and complicated due to the orofacial abnormalities involved and the altered nature of the tooth tissue. As both primary and permanent teeth are affected, diagnosis should be made during childhood and treatment should be started to avoid progressive damage and reduce the psychological impact to the patient. If the treatment is delayed, the clinical outcome may become more complicated and a multidisciplinary approach will be indicated. In the case presented, the orthodontic interventions can greatly facilitate the prosthetic planning so as to preserve the remaining tooth structure and optimize the space for the physical performance of the dental materials.

\section{CLINICAL SIGNIFICANCE}

This case report demonstrates the effective restoration of AI using a multidisciplinary approach to overcome crowding using a relatively conservative approach.

\section{ACKNOWLEDGMENTS}

The authors would like to express appreciation to the technical support by the staff of dental technology unit, The Prince Philip Dental Hospital in Hong Kong.

\section{REFERENCES}

1. Gadhia K, McDonald S, Arkutu N, Malik K. Amelogenesis imperfecta: an introduction. Br Dent J 2012 Apr;212(8):377-379.

2. Aldred MJ, Savarirayan R, Crawford PJ. Amelogenesis imperfecta: a classification and catalogue for the 21st century. Oral Dis 2003 Jan;9(1):19-23.

3. Poulsen S, Gjørup H, Haubek D, Haukali G, Hintze H, Løvschall H, Errboe M. Amelogenesis imperfecta - a systematic literature review of associated dental and oro-facial abnormalities and their impact on patients. Acta Odontol Scand 2008 Aug;66(4):193-199.

4. Witkop CJ Jr. Amelogenesis imperfecta, dentinogenesis imperfecta and dentin dysplasia revisited: problems in classification. J Oral Pathol 1988 Nov;17(9-10):547-553.

5. Marasa F. Crozat appliance treatment of buccal crossbite. J Clin Orthod 2003 Jun;37(6):329-334.

6. Wright JT, Hart TC, Hart PS, Simmons D, Suggs C, Daley B, Simmer J, Hu J, Bartlett JD, Li Y, et al. Human and mouse enamel phenotypes resulting from mutation or altered expression of AMEL, ENAM, MMP20 and KLK4. Cells Tissues Organs 2008 Dec;189(1-4):224-229.

7. Mårdh CK, Bäckman B, Holmgren G, Hu JC, Simmer JP, Forsman-Semb K. A nonsense mutation in the enamelin gene causes local hypoplastic autosomal dominant amelogenesis imperfecta (AIH2). Hum Mol Genet 2002 May;11(9):1069-1074.
8. Hu JC, Hu Y, Smith CE, McKee MD, Wright JT, Yamakoshi Y, Papagerakis P, Hunter GK, Feng JQ, Yamakoshi F, et al. Enamel defects and ameloblast-specific expression in Enam knock-out/lacz knock-in mice. J Biol Chem 2008 Apr;283(16):10858-10871.

9. Gibson CW, Yuan ZA, Hall B, Longenecker G, Chen E, Thyagarajan T,Sreenath T, WrightJT,DeckerS,PiddingtonR, etal. Amelogenin-deficient mice display an amelogenesis imperfecta phenotype. J Biol Chem 2001 Aug;276(34):31871-31875.

10. Wright JT, Hart PS, Aldred MJ, Seow K, Crawford PJ, Hong SP, Gibson CW, Hart TC. Relationship of phenotype and genotype in X-linked amelogenesis imperfecta. Connect Tissue Res 2003 Feb;44(Suppl 1):72-78.

11. Hart PS, Hart TC, Michalec MD, Ryu OH, Simmons D, Hong S, Wright JT. Mutation in kallikrein 4 causes autosomal recessive hypomaturation amelogenesis imperfecta. J Med Genet 2004 Jul;41(7):545-549.

12. Kim JW, Simmer JP, Hart TC, Hart PS, Ramaswami MD, Bartlett JD, Hu JC. MMP-20 mutation in autosomal recessive pigmented hypomaturation amelogenesis imperfecta. J Med Genet 2005 Mar;42(3):271-275.

13. Simmer JP, Hu Y, Lertlam R, Yamakoshi Y, Hu JC. Hypomaturation enamel defects in Klk4 knockout/LacZ knockin mice. J Biol Chem 2009 Jul;284(28):19110-19121.

14. Santos MC, Hart PS, Ramaswami M, Kanno CM, Hart TC, Line SR. Exclusion of known gene for enamel development in two Brazilian families with amelogenesis imperfecta. Head Face Med 2007 Jan;3(1):8.

15. Lee SK, Hu JC, Bartlett JD, Lee KE, Lin BP, Simmer JP, Kim JW. Mutational spectrum of FAM83H: the C-terminal portion is required for tooth enamel calcification. Hum Mutat 2008 Aug;29(8):E95-E99.

16. Wright JT, Frazier-Bowers S, Simmons D, Alexander K, Crawford P, Han ST Hart PS, Hart TC. Phenotypic variation in FAM83H-associated amelogenesis imperfecta. J Dent Res 2009 Apr;88(4):356-360.

17. Altug-Atac AT, Erdem D. Prevalence and distribution of dental anomalies in orthodontic patients. Am J Orthod Dentofacial Orthop 2007 Apr;131(4):510-514.

18. Bäckman B, Holm AK. Amelogenesis imperfecta: prevalence and incidence in a northern Swedish county. Community Dent Oral Epidemiol 1986 Feb;14(1):43-47.

19. Sedano HO. Congenital oral anomalies in argentinian children. Community Dent Oral Epidemiol 1975 Mar;3(2):61-63.

20. Chosack A, Eidelman E, Wisotski I, Cohen T. Amelogenesis imperfecta among Israeli Jews and the description of a new type of local hypoplastic autosomal recessive amelogenesis imperfecta. Oral Surg Oral Med Oral Pathol 1979 Feb;47(2):148-156.

21. Sundell S, Koch G. Hereditary amelogenesis imperfecta. I. Epidemiology and clinical classification in a Swedish child population. Swed Dent J 1985 Feb;9(4):157-169.

22. Wright JT, Deaton TG, Hall KI, Yamauchi M. The mineral and protein content of enamel in amelogenesis imperfecta. Connect Tissue Res 1995;32(1-4):247-252.

23. Wright JT, Duggal MS, Robinson C, Kirkham J, Shore R. The mineral composition and enamel ultrastructure of hypocalcified amelogenesis imperfecta. J Craniofac Genet Dev Biol 1993 Apr-Jun;13:117-126.

24. Seow WK, Amaratunge A. The effects of acid-etching on enamel from different clinical variants of amelogenesis imperfecta: an SEM study. Pediatr Dent 1998 Jan-Feb;20(1):37-42. 